\title{
Human DRL performance, collateral behavior, and verbalization of the reinforcement contingency*
}

\author{
NORMAN STEIN and STEPHEN FLANAGAN $\dagger$ \\ Syracuse University, Syracuse, N.Y. 13210
}

Adult human Ss, reinforced for keypressing on a DRL 5 -sec schedule of reinforcement, regularly verbalized hypotheses about the behavioral requirements necessary for obtaining reinforcement. High frequencies of overt collateral behavior accompanied response-based hypotheses and low or absent rates of overt collateral behavior accompanied time-based hypotheses. The findings support the conclusion that overt collateral responding can be functionally equivalent to mediative counting during temporally spaced responding.

Previous studies examining DRL performance in humans (e.g., Bruner \& Revusky, 1961; Laties \& Weiss, 1962; Randolph, 1965) have reported regular occurrences of collateral behavior between successively reinforced responses. Recently, Stein \& Landis (1973) documented the mediating role human collateral behavior can serve in regulating temporally discriminated DRL performance. In each of these studies, collateral behavior was expressed either overtly, as a chain of motor responses, or covertly, in the form of verbal mediators which emphasized either a time- or response-based self-instruction about the contingency of reinforcement. The present experiment examined the interrrelationships between overt and covert forms of collateral behavior and DRL performance as they occurred at regular intervals throughout training.

\section{METHOD \\ Subjects}

The Ss were 10 female introductory psychology students, who received class credit for participation. None had had previous experience with DRL schedules from either coursework or other experiments.

\section{Apparatus}

The Ss were seated in a room and fitted with a headphone, over which continuous white noise at $60 \mathrm{~dB}$ (re .0002 dynes $/ \mathrm{cm}^{2}$ ) was presented to mask extraneous sounds. In front of the $\mathrm{S}$ was a chassis containing four adjacent telegraph keys, placed $9.5 \mathrm{~cm}$ apart, each requiring a downward force of $438 \mathrm{~g}$ to be electrically recorded as a response. Directly above each key was a separate light which could be illuminated remotely. A four-digit counter was mounted in the middle of the chassis to indicate the cumulative number of reinforcements (points). A series of relays, timers, and recorders located in an adjacent room was employed to program events and record responses. A one-way mirror between the programming and $S$ rooms allowed continuous visual monitoring of $S$.

Each keypress activated a separate channel of an event recorder, with another channel recording reinforcements. The second key from S's right (Key 3) was programmed to produce reinforcement on a DRL $5-\mathrm{sec}$ schedule. Responses on the

*Sponsored by F. Robert Brush, Syracuse University, who takes full editorial responsibility for it.

tReprints are available from Norman Stein, 331 Huntington Hall, Department of Psychology, Syracuse University, Syracuse, N.Y. 13210 . additional three keys comprised the overt collateral behavior and had no effect on the timer governing reinforcement.

\section{Procedure}

Each $\mathrm{S}$ was run individually for $75 \mathrm{~min}$. The following instructions were presented at the beginning of the session:

"On the panel in front of you are four telegraph keys, a light above each key, and a point counter. Your task is to cumulate as many points as you can by pressing the keys. However, you may press only one key at a time with only one hand at a time.

"When you have earned a point, the red light above the counter will flash and a point will register on the counter. Your point score is a measure of your ability to learn or solve problems, so try to cumulate as many points as you can.

"As you are probably aware, a subject's thoughts about an experiment in which they are participating are important to take into account. From time to time, the lights above the keys will go out. At these times, please write briefly and clearly the reason or reasons that you responded in the manner in which you did. The booklet by your hand should be used, and after you write, please turn the page to signal you are ready to resume key pressing. Please wait for the lights to go on before you resume the task.

"For the first several minutes, you will not be able to earn points. During this period, please familiarize yourself with the apparatus by pressing the keys.

"Remember you may press only one key at a time using only one hand at a time. Try to get as many points as you can."

Questions were responded to with repetition of the instructions and evasive answers. Prior to the session, books, pocketbooks, watches, and jewelry were removed from S. During the initial $5 \mathrm{~min}$ of the session, no reinforcements were available. This allowed an assessment of S's baseline rate of responding. The acquisition phase consisted of 15 successive 3-min periods in which the DRL $5-\mathrm{sec}$ contingency on Key 3 was in effect. Each period was separated by a 45 -sec timeout period, during which $S$ wrote the reasons for responding during the preceding DRL training interval.

\section{RESULTS AND DISCUSSION}

Each of the Ss' 15 verbalizations was classified as reflecting either a time- or response-based hypothesis about the reinforcement contingency. A verbalization was classified as time-based $(T)$ if reference was made to waiting a duration of time as the essential condition for reinforcement, and was judged as response-based (R) if the verbalization referred to the necessity for pressing the collateral keys in order to obtain a reinforcement. If the Ss' statement expressed neither a time nor a response component (e.g., "no particular reason"), it was classified as "undetermined." The classifications were conducted by two experimentally naive judges who achieved an interrater agreement of $89 \%$.

Table 1 summarizes the relationships between the final type of verbalization and measures of DRL performance. At the end of training, four Ss verbalized a T-based hypothesis and six verbalized an R-based hypothesis about the reinforcement contingency. For each $\mathrm{S}$, the final verbalization was preceded by at least five consecutive verbalizations (i.e., last $15 \mathrm{~min}$ of training) in the same category. All Ss except $S 4$ initially 
Table 1

Performance During Last 15 Min and Throughout DRL Training as Related to S's Verbalization of the Reinforcement Contingency

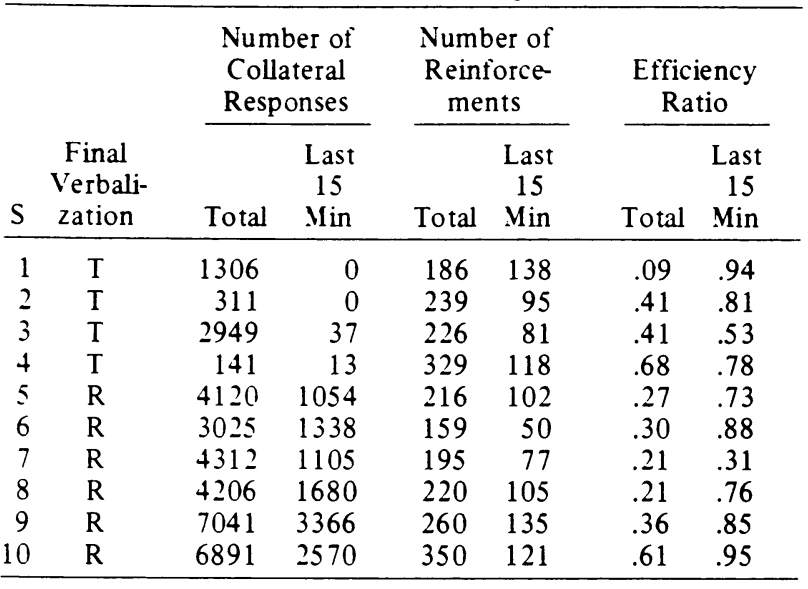

verbalized an R-based hypothesis. During the first five blocks of training, the verbalizations from S6 were classified as "undetermined," but beginning with the sixth block of training an R-based hypothesis was emitted. Ss who reliably verbalized a T-based hypothesis emitted substantially fewer collateral keypresses than Ss who verbalized an $R$-based hypothesis $(t=3.41, d f=8$, $\mathrm{p}<.005$, one-tailed test). However, the nature of the verbalization was unrelated to either the total number of reinforcements obtained or to the efficiency [(number of reinforced responses)/(total number of Key 3 responses)] of the performance. Thus, in the course of responding on a DRL schedule, perceiving the nature of the reinforcement contingency as either time- or response-based was manifested predominantly in the frequency of overt (motor) collateral behavior, but was

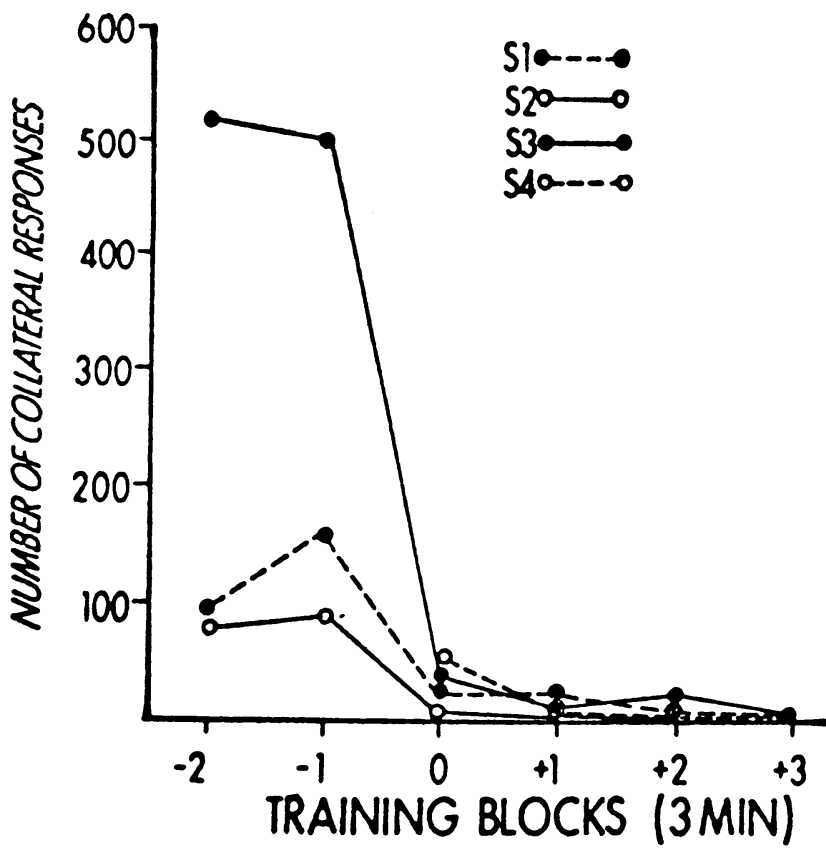

Fig. 1. Number of collateral responses for each $S$ during successive 3-min DRL training blocks prior to and after verbalization of a time-based contingency of reinforcement. largely unrelated to the $\mathrm{S}$ 's adjustment to the reinforcement schedule or to the efficiency of performance. Also, no significant relationship emerged between the rate of baseline responding and the probability of subsequently developing a time- or a response-based hypothesis during training $\left(\mathrm{r}_{\mathrm{pb}}=.28, \mathrm{t}=\right.$ .82 , $\mathrm{df}=8, \mathrm{p}>.05)$. This is in contrast to verbalizations about the contingency following training on fixed interval schedules of reinforcement, in which lower initial response rates were associated with the development of time-based hypotheses and faster initial response rates were related to the subsequent development of response-based hypotheses (Leander, Lippman, \& Meyer, 1968).

The specific relationship between the emergence of a time-based hypothesis and changes in the frequency of overt collateral behavior for each $S$ finally verbalizing a time-based hypothesis is depicted in the backward learning curves shown in Fig. 1. The zero point on the abscissa refers to the DRL period following which the $S$ first verbalized the time-based contingency of reinforcement. Negative integers denote the preceding periods, while positive integers indicate the DRL periods following verbalization of a temporal contingency. As shown, for Ss 1,2 , and 3, the transition from verbalizing an $\mathrm{R}$ hypothesis to a $\mathrm{T}$ hypothesis was accompained by an immediate reduction and, in effect, an elimination in the occurrence of collateral keypressing. S 4 indicated a $\mathrm{T}$ hypothesis following the first 3-min interval of training and, thus, there were no contrasting preceding periods of collateral behavior correlated with R-based hypotheses. However, the collateral response rates which accompanied the $\mathrm{T}$-based hypotheses were consistent with those of the other Ss. Moreover, there were no reliable changes in either the number of reinforcements obtained or in the efficiency of performance that accompanied the shifts from an $R$ to a $T$ hypothesis. As shown in Table 1, Ss that maintained an $\mathrm{R}$ hypothesis continued to exhibit a high rate of overt collateral responding, as shown during the last $15 \mathrm{~min}$ of DRL training. Together with the previous findings, these results add further support to the conclusion that high rates of overt collateral behavior, which accompanied the response-based hypotheses, were functionally equivalent to the covert time-based hypotheses in mediating human DRL performance.

\section{REFERENCES}

Bruner, A., \& Revusky, S. H. Collateral behavior in humans. Journal of the Experimental Analysis of Behavior, 1961,4, 349-350.

Laties, V. G., \& Weiss, B. Effects of alcohol on timing behavior. Journal of Comparative \& Physiological Psychology, 1962, 55. 85-91.

Leander, J. D., Lippman, L. G., \& Meyer, M. E. Fixed interval performance as related to subjects' verbalizations of the reinforcement contingency. Psychological Record, 1968, 18 , 469-474.

Randolph, J. J. A further examination of collateral behavior in humans. Psychonomic Science, 1965, 3, 227-228.

Stein. N., \& Landis, R. Mediating role of human collateral behavior during a spaced-responding schedule of reinforcement. Journal of Experimental Psychology, 1973, 97, 28-33.

(Received for publication September 27, 1973.) 